\title{
Vidas negras importam? a urgência de pensar a educação antirracista frente aos impactos da pandemia de COVID-19
}

\author{
Do black lives matter? The urgency of thinking anti-racist education in front \\ of the impacts of the COVID-19 pandemic
}

\author{
Fernanda Carla da Silva Costa \\ Mestra em Ciência da Informação \\ Universidade Federal do Rio de Janeiro e \\ Instituto Brasileiro de Informação em Ciência e Tecnologia - UFRJ e IBICT. \\ Rio de Janeiro, RJ - Brasil. \\ costacs.fernanda@gmail.com \\ Viviane Lima Martins \\ Doutora em Comunicação e Semiótica \\ Instituto Federal de Ciência e Tecnologia - IFMG \\ Arcos, MG - Brasil. \\ viviane.martins@ifmg.edu.br
}

\begin{abstract}
Resumo: Em março de 2020, a Organização Mundial de Saúde (OMS) declarou como pandemia a COVID19, doença infecciosa que se espalhou pelo mundo, tornando-se necessárias diretrizes de contenção para redução de sua transmissão. O impacto dessas medidas foi sentido em âmbito gerais, intensificando a crise político-econômica em boa parte do mundo, o que tornou mais visível as desigualdades sociais, fruto de questões de raça, gênero e classe. Nesse momento, fontes de informação passam a mostrar as consequências disso, a partir do assassinato de George Floyd, nos Estados Unidos da América (EUA), morto em maio do mesmo ano, por um policial branco, através de asfixia, emergindo, assim, uma série de protestos antirracistas e contra violência policial. No Brasil, esses protestos se juntam a tantos outros casos em debate, como o do menino João Pedro de 14 anos, morto em uma operação policial no complexo do Salgueiro (RJ). Isso tudo, acende debates em torno do racismo, colocado, tantas vezes, como prática vinculada a falta de informação e educação. A partir dessas colocações, questionamos: por que precisamos pensar o antirracismo no contexto da educação na pandemia e no pós-pandemia? Para além, buscamos refletir, a partir de uma base metodológica de revisão de literatura, sobre o racismo e a educação e suas ligações intrínsecas com várias facetas da vida cotidiana e das necessidades do antirracismo como ferramenta de enfrentamento das desigualdades.
\end{abstract}

Palavras-chave: Educação antirracista. Racismo. Pandemia COVID-19.

Abstract: In March 2020, the World Health Organization (WHO) declared COVID-19, an infectious disease that spread throughout the world, as a pandemic, making containment guidelines necessary to reduce its transmission. The impact of these measures was felt at a general level, meaning an intensification of the political-economic crisis in much of the world, making social inequalities more visible, the result of issues of race, gender and class. At that moment, sources of information began to show the consequences of this, starting with the murder of George Floyd in the United States of America (USA), killed in May, by a white policeman, through suffocation, thus emerging a series of anti-racist protests and against police violence. In Brazil, these protests join so many other cases under debate, such as that of the boy João Pedro, 14, killed in a police operation in the Salgueiro complex (RJ). All of this sparks debates around racism, which has been put up so often, as a practice linked to a lack of information and education. Based on these statements, we ask: why do we need to think about anti-racism in the context of education in the pandemic and in the postpandemic? in addition, we seek to reflect from a methodological basis of literature review on racism and education in the intrinsic links with various facets of daily life and the needs of anti-racism as a tool to tackle inequalities. 
Keywords: Anti-Racist Education. Racism. Pandemic COVID-19.

1 Introdução

O mundo já passou por diversas pandemias, especialmente as de influenza ou gripe, consideradas infecções que mais causaram mortes, até a atualidade, exatamente pela alta capacidade de transmissão e distribuição global (COSTA, MERCHAN-HAMANN, 2018). Apesar da COVID-19 ser uma doença respiratória infecciosa, com transmissão parecida com a influenza, a velocidade da propagação é diferente, além dos números de infecções secundárias também estarem se mostrando mais altos.

A Síndrome Respiratória Aguda Grave (SARS - sigla em inglês) é causada pelo coronavírus, que tem uma ampla família, mas apenas alguns desses infectam humanos. Não é a primeira vez que a SARS se propaga, porém, dessa vez, a doença tomou contornos maiores, passando a ser divulgada como acontecimento a partir de dezembro 2019, com seu surgimento na cidade de Wuhan, na China, onde houve o indicativo dos primeiros casos. Todavia, a doença se espalhou pelo mundo, sendo estabelecida pela Organização Mundial de Saúde (OMS) como pandemia a partir de março de 2020, necessitando de estratégias para enfrentamento e diminuição do ritmo de contágio, sendo a principal delas o método de isolamento social.

Com isso, as atividades comerciais, de lazer, escolares e afins foram brecadas de forma quase instantânea, o que afetou o cotidiano social das pessoas. Esse processo vem sendo estudado e entendido, pouco a pouco, afinal, ainda estamos vivendo o momento e pensando em soluções para o futuro próximo. A cada descoberta da ciência sobre o COVID-19, o comportamento de interações sociais precisa ser readequado e as medidas de contenção reavaliadas.

Uma situação como essa torna mais visível todo mal das desigualdades sociais, já que as atividades econômicas mudaram, impactando o dia a dia através do desemprego, fome, falta de habitação e precarização do trabalho. Ligado a tudo isso temos o fator do racismo estrutural, que silencia o grande impacto da pandemia na vida de alguns sujeitos, como negros e indígenas, pessoas que em grande maioria vivem com difícil acesso a serviços públicos e direitos sociais.

Silvio Almeida, em seu livro Racismo Estrutural (2018), faz um compilado do conceito, mostrando como o racismo passa por todas as estruturas da sociedade, sendo gestado de um processo político-histórico de ideologias, no sentido lógico e tecnológico, das formas de desigualdade e violência. Tudo isso é gerado no seio do colonialismo como estrutura de nossa sociedade. 
Existe, então, uma urgência de pensarmos o impacto da pandemia de COVID-19, a partir das questões raciais, pois se silenciamos esse debate, transformamos as consequências em acontecimentos homogêneos, que não têm resposta das políticas públicas para reparação minimamente justa.

Quando falamos do racismo, estamos colocando uma estrutura de poder e projeto de segregação social, que é fundada dentro da colonialidade, como modo de vida histórico, vindo desde as explorações europeias pelo mundo, que impõe os modelos discursivos-políticos da modernidade, junto ao modelo universal do homem branco, que tem a dominação cultural, da informação e conhecimento a partir das colonizações.

Ao levarmos em consideração a situação de calamidade sanitária, necessitamos pensar a saúde como um dos principais norte durante a pandemia, questionando como diferentes populações são extremamente afetadas pelo racismo no acesso a saúde, o que aumenta em todos os níveis as vulnerabilidade de grupos, implicando em suas próprias vidas e nas dificuldades de contenção da pandemia, visto a impossibilidade de diálogo com o Estado (KALCKMANN, et al., 2007).

A partir dessa conjuntura, começamos a ver o que a pandemia tem descortinado acerca do racismo e das necessidades das constantes lutas antirracistas, pois as interseccionalidades que atingem esses grupos, expõem como estão sofrendo e pagando com a própria vida, seja os abalos econômicos ou as inúmeras violências físicas e psicológicas que sofrem.

Uma série de acontecimentos ganhou repercussão a partir do alerta constante da militância negra sobre o impacto da COVID-19 nestas populações. Podemos citar os protestos antirracistas desencadeados mundialmente, após o assassinato de George Floyd, estrangulado por um policial branco, com o joelho em seu pescoço, durante uma abordagem policial, devido ao fato de o suspeito ter feito, supostamente, uso de uma nota falsificada em um supermercado na cidade de Minneapolis (EUA). No Brasil, temos o caso do menino João Pedro, 14 anos, morto em uma operação policial no complexo do Salgueiro (RJ), o sumiço e a morte de Gabriel, 18 anos, em Natal (RN), também, possivelmente, envolvendo a polícia, além do caso de Miguel, 5 anos, que morreu ao cair do $9^{\circ}$ andar de um prédio, por negligência da patroa de sua mãe, que estava com ele por alguns instantes, enquanto a mãe, empregada doméstica, passeava com os cachorros ao lado de fora do prédio.

Esses acontecimentos geraram discussões e movimentações, pois têm em comum as vidas negras. Dessa forma, foram motivando tags e protestos, representados pelas hashtags 
\#blacklivesmatter e \#vidasnegrasimportam, que circularam no Brasil e no mundo, sendo centradas e difundidas a partir das mídias sociais.

Em meio a tantas discussões sobre a pandemia, os problemas sociais nas periferias, a violência policial e o impacto nas vidas negras, muitas vezes, o discurso sobre esses acontecimentos é colocado como falta de informação e educação. Isso nos faz pensar no papel da educação e questionarmos: por que precisamos pensar o antirracismo no contexto da educação na pandemia e no pós-pandemia? Esse questionamento se encontra com as colocações de Grada Kilomba (2019), que diz sobre os sujeitos brancos terem respostas intelectualizadas e racionalizadas para construir uma lógica para o racismo, procurando reduzir os desejos inconscientes e agressivos em relação aos outros.

A educação antirracista se articula, diante disso, como um pensamento que vai além dos conteúdos, envolvendo uma gama de problemas, desde a discriminação racial/gênero/classe à evasão escolar. Por isso, uma ação didática antirracista mobiliza uma mudança profunda, ao mesmo tempo cognitiva e emocional, em uma batalha cotidiana para que crianças e jovens negros se considerem e se reconheçam dentro da negritude, estabelecendo que isso não é uma operação que tem efeitos apenas a partir da técnica-didática e planejamento, pois o racismo é profundamente ligado à dor e à violência (OLIVEIRA, 2020).

Um olhar conceitual a partir da obra de Bell Hooks (2013), Ensinando a transgredir: a educação como prática da liberdade, mostra que não existe uma separação entre teorias e práticas para educação, atrelando a educação ao antirracismo, antissexismo e antihomofobia, como uma prática do indivíduo e do coletivo. Como teórica negra feminista, a autora busca pautas por uma educação humanista, reconhecendo as peculiaridades das vozes dos indivíduos.

Buscamos levar em consideração, aqui, um diálogo entre as produções acadêmicas, os movimentos sociais e as representações e discussões a partir de variadas fontes de informação (jornal, youtubers, instagramers), visto que nossa vida, nesse momento, passou a ser ainda mais mediada pelo ciberespaço, optando-se por articular conceitos e reflexões, que consideramos já existentes no campo educacional e, que nesse momento, podem ser abordadas com a criticidade de pensar a educação antirracista como necessidade e ferramenta de enfrentamento. 


\section{Colonialidade, relações raciais e racismo}

Quando escrevemos/falamos sobre colonialidade, relações raciais e racismo, discutimos a partir de uma perspectiva que descentralize sempre as mesmas culturas brancas estudadas, historicamente racionalizadas, como objeto de conhecimento, poder e crítica cultural, reavaliando as perspectivas nacionais e nacionalistas, ligadas ao Estado-nação moderno como unidade política, econômica e cultural, filiado aos discursos de raça (GILROY, 2001).

A partir da ideia de Índias Ocidentais e do Novo Mundo, é precedida, também, a ideia de Brasil, todas inventadas com base na exploração territorial, que apagou outras memórias e justificou a supressão e genocídio. Isso justifica a modernidade universal, como interpretação de certo eventos por atores/instituições que atribuem a solução da humanidade a retóricas de suas expressões mais recentes representadas pelo desenvolvimentismo e globalismo (MIGNOLO, 2015).

Disso emerge a colonialidade com conjunto de princípios baseados na narrativa salvacionista e triunfalista de modernidade, construído pela justificativa de expropriação e exploração. O termo se legitimou como código conceitual, fundamentado na ideia de civilização ocidental, permeada pela ocidentalização como conjunto de projetos globais, sempre em mutação e adaptação (MIGNOLO; PINTO, 2015).

A nossa formação como sociedade é sustentada nessas ideias, com toda subjetividade que exalta os fundamentos patriarcais e raciais, convencionando as desigualdades de representação das identidades sociais, classe, raça, gênero, casta, cor, etnia, origem nacional/regional, orientação sexual, como vivências que fazem diferença na forma que os sujeitos experienciam a discriminação.

O próprio entendimento de raça é uma construção europeia e norte-americana, com discurso baseado no construto político e social, categorizando o conceito em torno do qual se organiza um sistema de poder. Além da nossa construção colonial, na nossa história política, não temos a superação colonial com os moldes de construção social da República, que tem como cerne a formação da "nação brasileira" toda em torno da questão racial, se apegando à ideia de limpeza social da eugenia (PEREIRA, 2013).

Esse histórico de colonização e escravismo ainda afeta, negativamente, a vida, a trajetória e a inserção social dos não-brancos, bem como o Estado nunca se posicionou política e ideologicamente, de forma enfática, contra essa estrutura do colonialista. Temos uma estrutura 
que se constitui de práticas e políticas públicas que desconsideram a desigualdade racial como resultante do processo de negação da cidadania aos negros (GOMES, 2005).

O racismo afeta o status de subjetividade das pessoas, ou seja, na construção dessa diferença a pessoa é vista a partir de valores hierárquicos, não sendo apenas o indivíduo diferente, mas também articulado através do estigma, da desonra e da inferioridade: problemático, difícil, perigoso, preguiçoso e afins. Esses pontos são a projeção do que a sociedade branca transformou em tabu, formando o que Grada Kilomba (2019) articula por Racismo Cotidiano, que se refere a todo vocabulário, discurso, imagem, gestos, ações e olhares, que colocam sujeitos de cor em aspectos reprimidos na sociedade branca, sempre o colocando como o outro, tornando-se a personificação daquilo que o sujeito branco não quer ser reconhecido.

Assim, o Racismo Cotidiano não se refere a uma experiência pontual, mas uma constelação de experiências de vida, uma exposição constante ao perigo, um padrão contínuo de abuso, que se repete incessantemente ao longo da biografia de alguém, no ônibus, no supermercado, em uma festa, no jantar e na família. Funciona, portanto, para justificar e legitimar a exclusão de outros raciais de certos direitos (KILOMBA, 2019).

\section{Urgência de pensar a educação antirracista no contexto da pandemia e no futuro pós- pandemia}

Quando falamos na urgência da temática de uma educação antirracista, queremos precisar que já existia essa emergência em tempos anteriores, dada nossa historicidade de colonização, falta e dificuldade de acesso dos subalternizados à educação. Gomes (2005) defende que falar sobre as questões raciais brasileiras ajuda na desmistificação do racismo e na superação da discriminação racial. Quando evidenciamos isso no contexto de pandemia, tornamos dizível e passível de ação a construção de reflexões, práticas e estratégias de superação das dificuldades da educação e da escola no pós-pandemia quando tratamos de educação antirracista.

Oliveira (2020), em seu artigo Opção decolonial e antirracismo na educação em tempos neofascistas, explana que, no momento em que vivemos, nossas Diretrizes Curriculares Nacionais para Educação das Relações Étnico-Raciais e para o Ensino de História e Cultura Afro-Brasileira e Africana se encontram ameaçadas pelas guerrilhas neoconservadoras fascistas, como foi o caso da aprovação do Novo Ensino Médio, em 2016, que destitui a 
disciplina de História como obrigatória, tornando ainda mais difícil a aplicação da lei 10.639/03 sobre o Ensino da História e Cultura Afro-Brasileira.

Porém, acreditamos, em consonância com Oliveira (2020), que pensar a importância da educação antirracista no contexto em que vivemos não se trata apenas do processo de didatização dos conteúdos e materiais antirracista, mas, também, dos debates sobre evasão escolar, repetência e os ditos "aluno(a)s problemático(a)s" (na maioria dos casos os/as jovens com marcas raciais).

A partir do Observatório de Educação (INSTITUTO UNIBANCO, 2020), que faz curadoria de informações/dados com Indicadores Educacionais sobre Qual a diferença no acesso à educação para Brancos e Negros?, as desigualdades educacionais são ressaltadas no contexto cor/raça/socioeconômico a partir dessas características. Esse repositório disponibiliza dados do Censo Escolar do Instituto Nacional de Estudos e Pesquisa (INEP) de 2018, onde 7,8\% dos estudantes negros abandonam o Ensino Médio contra 5\% dos casos de estudantes brancos.

Tendo este cenário, sabemos que esses jovens abandonam a escola, em sua grande maioria, pela necessidade de trabalhar, como entregadores de alimento/medicamento, caixas/auxiliar de supermercado, serviços que, nesse momento estão mais expostos a COVID19. Isso quando esses jovens conseguem se manter trabalhando e não são cooptados pela violência e/ou pelo encarceramento em massa. Frente a essas constatações, como será garantido o retorno desses jovens a escola?

A escola está frente a essas condições, como local de mobilização de reflexões permanentemente, o que passa pelas angústias, tristezas, dores, medos, humilhações e tantos outros sentimentos que o racismo produz de forma negativa (OLIVEIRA, 2020). Não parecem ser estes muitos dos sentimentos mobilizados pela pandemia e o isolamento social? Como podemos imaginar a saúde desses alunos, agora, e em relação ao futuro incerto? A educação desses tempos e do tempo posterior pode oferecer ferramentas capazes reverberar em uma melhor qualidade de vida e saúde emocional?

Dentre as medidas de contenção, a paralisação das escolas foi uma das mais necessárias e com maior impacto para o futuro. Ainda que se adote o ensino remoto - de modo que os conteúdos que são ministrados presencialmente passam a ser mediados por outros meios - ou o formato $\mathrm{EAD}$, com outro tipo de planejamento para os conteúdos, muitas são as problemáticas 
sócio-técnicas: com aulas online muitos não têm acesso a computador/smartphone/internet, quando não é isso, falta ambiente propício ao estudo e adultos escolarizados para auxiliar.

Questões como espaço físico e necessidade de cuidar de outras pessoas dependentes não deixam de ser, também, uma realidade para os professores, além do fato que dada a formação das duas gerações de professores, que encontramos em atuação, muitos têm pouca experiência para lecionar remotamente utilizando as Tecnologias da Informação e Comunicação (TIC).

Ainda cabe destacar que, em meio a esse colapso de acesso à escola, o ministro da educação à época defendeu seguir normalmente o calendário do Exame Nacional do Ensino Médio (ENEM) 2020. Em propaganda para inscrição no exame (BRASIL, 2020), personagens de alunos aparecem equipados, em lugares de estudo estruturados, dizendo coisas como "estude, de qualquer lugar, de diferentes formas, pelos livros, internet, com a ajuda a distância dos professores".

Perceptível como a ideologia da meritocracia está imbuída de reger a educação do país, em especial nesse momento, predominando um pensamento que só alimenta as desigualdades e não considera que os alunos que prestam esse exame, partem de condições totalmente diferentes para estudo. Foi necessária grande movimentação social, judicial e legislativa para que a prova fosse adiada e feita uma consulta aos inscritos de em qual nova data poderiam ser realizadas as provas. Mesmo assim, sabemos que o impacto na organização dos estudos e no acesso a cursinhos populares vai ser sentida por uma maioria negra periférica, que já se sente a margem de acessar o ensino superior.

Não podemos naturalizar a diferença do impacto da raça nessas circunstâncias, aqui pensadas sob o viés da educação, pois ele não atinge da mesma forma brancos, negros e indígenas (parte mais representativa das raças no Brasil), mas, nessa permanência e acesso escolar, muitas outras variantes são relevantes. A situação fica ainda mais específica quando pensamos na Educação de Jovens e Adultos (EJA), que similarmente comporta alunos em sua maioria trabalhadores, negros e periféricos, que não puderam se manter no tempo regular do Ensino Básico.

Esse não deixa de ser um grupo marcado pelas interseccionalidades de raça, classe e gênero, como demonstra Isabela Palhares, em matéria da Folha de São Paulo, em 2 junho de 2020, sobre o EJA, Escolas temem que adultos abandonem estudos pós-pandemia do coronavírus. Ela descreve que o ensino remoto não tem ajudado a esse grupo, principalmente por trabalharem de forma remunerada/não remunerada, não terem habilidades para usar 
equipamentos eletrônicos e acabam com vínculos mais frágeis com a vida escola. Em suma, esse é um grupo muito afetado pela crise econômica e o acesso material aos aparatos de estudo.

Já na matéria da Revista Exame, escrita por Ligia Toon, em junho de 2020, vemos a interseccionalidade das opressões nos dados do Instituto Locomotiva, a partir do estudo sobre quem solicitou o auxílio emergencial destinado pelo Governo Federal à população mais vulnerável. No levantamento, os negros são os que mais solicitaram o auxílio, mas são, também, o grupo com menor número de concessões. Essa pesquisa faz parte de um estudo maior que mostra como o racismo no Brasil é arraigado, e que, assim, a população negra tem sentido mais os efeitos econômicos do COVID-19 na diminuição da renda.

Quando tratamos do aspecto saúde, a Política Nacional de Saúde Integral da População Negra - Uma Política do SUS, traz dados que o Instituto de Pesquisa Econômica Aplicada (IPEA) já havia produzido, em 2008, nos quais a população negra representava $67 \%$ dos atendidos pelo SUS. Os dados também identificam como essa população é mais suscetível biologicamente e demograficamente (BRASIL, 2017), o que apresenta estes como um grande contingente de grupo de risco.

Isso também é explicado por motivos históricos, haja vista que os negros são mais vulneráveis por condições ancestrais, haja vista que viveram em sua maioria com baixas condições sanitárias, adquirindo predisposições genéticas da escravização. Basta pensar que essas pessoas foram trazidas à força, em longas viagens no porão de navios, expostos à desidratação, diarreia, e que só chegavam vivas aquelas que tinham maior capacidade de reter sal e, consequentemente, água, sendo esse um fator que que faz dessa população uma herdeira da pressão alta, dentre tantas outras doenças, consequentes de outras violências, como anemia falciforme e diabetes.

A omissão da herança colonial, da escravidão e do racismo espelha a desimportância dos negros como sujeitos políticos, sociais e individuais na política. Tais discursos sobre a situação de vida dos negros só se tornam visíveis nas esferas públicas e acadêmicas quando a normalidade da cultura nacional branca é subitamente perturbada, quando as experiências com o racismo colocam em risco o conforto da sociedade branca (KILOMBA, 2019). Apenas nesse momento a negritude se torna visível, faladas e até mesmo escrita, como temos visto no movimento em que artistas brancos estão cedendo suas contas nas redes sociais digitais, com milhares de inscritos, para que influencers negros tenham lugar de fala mais ampliado nessas redes e discutam sobre os acontecimentos atuais. 
Esse movimento nas redes sociais digitais, principalmente no Instagram, tem sido necessário para promover a autopercepção e autodeterminação dos negros, promovendo a militância, os eventos e a produção de conhecimento descentralizado dos dominantes, o que significa também uma promoção da educação em ambientes não-formais, como terreiros, coletivos, igrejas e Ongs, quando estes espaços são pautados na diversidade. A sociedade brasileira procura colocar todos em tom de igualdade, silenciando a existência do racismo, mas no cotidiano, as pesquisas atestam que nas relações de gênero, no mercado de trabalho, na educação básica e na universidade, em todos esses espaços e em muitos outros, os negros continuam sendo discriminados e vivendo em situação de profunda desigualdade racial (GOMES, 2005).

Como a realidade do racismo é reproduzida em todos os lugares, como por exemplo, nos comentários das mídias sociais digitais, nos discursos acadêmicos, através de epistemologias e métodos, não se dá a estes sujeitos o direito à autorrepresentação. Por isso, quando pensamos na intersecção das opressões, não estamos simplesmente sobrepondo camadas, mas sim, pensando no efeito de produção específico de cada uma dessas (KILOMBA, 2019).

Na junção de todos esses lados explicitados, deixamos aqui a importância de falar sobre esses acontecimentos na educação. Como dito por Hooks (2013), o silêncio pode ser um ato de cumplicidade para que nos tornemos desengajados nas lutas coletivas.

\section{Considerações finais ou 'que futuro sonhamos para educação pós-pandemia no Brasil?'}

Fizemos, aqui, um exercício para pensar o cenário em que nós encontramos juntamente com as questões raciais e da educação. Hooks (2013, p. 103) muito consciente da nossa historicidade dolorida, diz: "Não é fácil dar nome à nossa dor, teorizar a partir desse lugar". A escola e a educação já passam por problemas de recurso e gestão que são anteriores à pandemia, agora o que precisamos questionar é como isso irá se agravar, e quais indicadores sociais irão se tensionar ainda mais.

A ideologia colonialista molda e media a nossa concepção de mundo, e a educação aparece como mecanismo, muitas vezes, utilizado para respaldar e legitimar ideias de que somos todos iguais, e que bastam interesse e resiliência para alcançar o que almejamos, naturalizando, no cotidiano, a meritocracia como meio de merecimento para acessar informação e conhecimento. 
Quando levantadas essas questões teóricas e do cotidiano, percebemos que a desnaturalização do discurso de igualdade na educação é necessária para o antirracismo, como é necessário, também, para professores e gestores compreenderem o peso da desigualdade racial, construindo ações específicas e voltadas para a permanência e continuidade desses alunos.

Ao pensarmos o futuro da escola e da educação, no pós-pandemia, que instrumentos pensaremos para criatividade, emancipação, realização, mobilidade social e formação desses sujeitos? Como diz Paulo Freire (2000), "Se a educação sozinha não transforma a sociedade, sem ela tampouco a sociedade muda.”.

Que não esqueçamos que essa é uma luta que vai além das pautas negras. Nossos ancestrais indígenas também enfrentam, neste momento, dificuldades parecidas e outras tantas diferentes. Que a voz deles também seja ouvida por todos, que procuremos as mídias de informação indígena para lutar contra o genocídio das nossas existências.

Mais que uma tarefa da escola, dos professores, é necessária uma ação conjunta de militantes, acadêmicos, intelectuais negros e não negros e comunidade, como tarefa política de insurgência da juventude negra na escola do pós-pandemia, socializando a educação antirracista, que pense no gênero, na sexualidade e na classe social, com a intenção de uma pedagogia libertadora, baseada em políticas públicas de equidade racial.

\section{Referências}

BRASIL. Ministério da Saúde. Política Nacional de Saúde Integral da População Negra: uma política para o SUS. Brasília: Editora do Ministério da Saúde, 2017. Disponível: https://bit.ly/3eYKQGN. Acesso em: 24 jun. 2020.

BRASIL. Ministério da Educação. ENEM 2020 inscrições, 2020. Disponível em: https://www.youtube.com/watch?v=apufjiGlIY0. Acesso em: 29 jun. 2020.

CANECO, Cássia; TAVARES, Jessica; MEDINA, Graciela. Quem tem o direito de sonhar um futuro pós-pandemia no Brasil? Nexo, 15 mai. 2020. Disponível em: https://bit.ly/3eNPDdJ. Acesso em: 25 jun. 2020.

CARDOSO, Ivanilda Amado. Por que a o COVID-19 nos obriga a repensar a nossa concepção de educação? Portal GELEDES, 8 de mai. 2020. Disponível em: https://bit.ly/3ihJYPi.Acesso em: 24 jun. 2020.

COSTA, Ligia Maria Cantarino da; MERCHAN-HAMANN, Edgar. Pandemias de influenza e a estrutura sanitária brasileira: breve histórico e caracterização dos cenários. Revista Pan- 


\section{Dialogia}

COSTA, Fernanda Carla da Silva; MARTINS, Viviane Lima. Vidas negras importam? a urgência de pensar a educação antirracista frente aos impactos da pandemia de COVID-19

Amazônica de Saúde, v. 7, n. 1, 2018. Disponível em: https://bit.ly/2YMuBXv. Acesso em: 26 jun. 2020.

FREIRE, Paulo. Pedagogia da Indignação: cartas pedagógicas e outros escritos. São Paulo: Editora UNESP, 2000.

GILROY, Paul. O Atlântico Negro: modernidade e dupla consciência. Rio de Janeiro: Editora 34/Universidade Cândido Mendes, 2001.

GOMES, Nilma Lino. Alguns termos e conceitos presentes no debate sobre relações raciais no Brasil: uma breve discussão. In: História: coleção para todos. Brasília: Ministério da Educação, 2005.

HOOKS, Bell. Ensinando a transgredir: a educação como prática da liberdade. São Paulo: Editora Martins Fontes, 2013.

INSTITUTO UNIBANCO. Observatório de Educação do Ensino Médio e Gestão. Educação em Número: Desigualdade Racial. Disponível em: https://bit.ly/2NJVCV4. Acesso em: 20 jun. 2020.

KALCKMANN, Suzana et al . Racismo institucional: um desafio para a eqüidade no SUS? Saúde soc., São Paulo, v. 16, n. 2, p. 146-155, 2007 . Disponível em: https://bit.ly/38eMOA1. Acesso em: 24 jun. 2020.

KILOMBA, Grada. Memórias da Plantação: Episódios de Racismo Cotidiano. Cobogó: Rio de Janeiro, 2019.

MIGNOLO, Walter; PINTO, Júlio Roberto de Souza. A modernidade é de fato universal? Reemergência, desocidentalização e opção decolonial. Civitas, v. 15, n. 3, 2015.

MIGNOLO, Walter. Colonialidade: o lado mais escuro da modernidade. Revista Brasileira de Ciências Sociais. v. 32, n. 94, 2017.

NOGUEIRA, Fernanda. Pandemia de coronavírus deve piorar desigualdade racial no Ensino Médio. Porvir.org, 19 mai. 2020. Disponível em: https://bit.ly/3ii31sH. Acesso em: 27 jun. 2020.

OLIVEIRA, Luiz Fernandes de. Opção decolonial e antirracismo na educação em tempos neofascistas. Revista da ABPN, v. 12, n. 32, 2020. Disponível em: https://bit.ly/3eNpWdx. Acesso em: 29 jun. 2020.

PALHARES, Isabela. Escolas temem que adultos abandonem estudos após pandemia do coronavírus. Jornal folha de São Paulo, 2 jun. 2020. Disponível em: https://www1.folha.uol.com.br/educacao/2020/06/escolas-temem-que-adultos-abandonemestudos-apos-pandemia-do-coronavirus.shtml. Acesso em: 25 jun. 2020.

PEREIRA, Amilcar. $O$ mundo negro: relações raciais e a constituição do movimento negro no Brasil. Rio de Janeiro: Pallas/FAPERJ, 2013. 


\section{Dialogia}

COSTA, Fernanda Carla da Silva; MARTINS, Viviane Lima. Vidas negras importam? a urgência de pensar a educação antirracista frente aos impactos da pandemia de COVID-19

SANTANA, Irapuã. Por que negros morrem mais: o racismo institucional no acesso à saúde. Nexo, 12 mai. 2020. Disponível em: https://bit.ly/3dSX16F. Acesso em: 29 jun. 2020.

TUON, Ligia. Negros pediram mais auxílio emergencial, mas brancos tiveram maior sucesso. Revista exame, 17 jun. 2020. Disponível em: https://exame.com/brasil/negros-pediram-maisauxilio-emergencial-mas-brancos-tiveram-maior-sucesso/. Acesso em: 29 jun. 2020.

ZANLORENSSI, Gabriel; GOMES, Lucas. A distribuição do auxílio emergencial por condição e por estado. Nexo, 24 jun. 2020. Disponível em: https://bit.ly/3dLwdFd. Acesso em: 29 jun. 2020.

Recebido em: 16 ago. 2020/ Aprovado em: 13 nov. 2020

Cite como

(ABNT NBR 6023:2018)

COSTA, Fernanda Carla da Silva; MARTINS, Viviane Lima. Vidas negras importam? A urgência de pensar a educação antirracista frente aos impactos da pandemia de COVID-19. Dialogia, São Paulo, n. 36, p. xx-xx, set./dez. 2020. Disponível em: https://doi.org/10.5585/dialogia.n36.17917.

\section{American Psychological Association (APA)}

Costa, F. C. S., \& Martins, V. L. (2020, set./dez.). Vidas negras importam? a urgência de pensar a educação antirracista frente aos impactos da pandemia de COVID-19. Dialogia, São Paulo, 36, p. xx-xx. https://doi.org/10.5585/dialogia.n36.17917. 